\title{
A VIOLAÇÃO DA SEGURANÇA JURÍDICA NO PROCESSO DE ANULAÇÃO DEMARCATÓRIA PANAMBI LAGOA RICA FACE AOS DOS DIREITOS HUMANOS
}

\section{THE VIOLATION OF LEGAL SECURITY IN THE PANAMBI LAGOA RICA DEMARCATING CANCELLATION PROCESS ON HUMAN RIGHTS}

\author{
Julia Thais Moraes, Marco Aurélio Raniéri
}

Resumo: O presente trabalho visa analisar como a anulação do território tradicional Panambi Lagoa Rica dos guarani kaiowá em Mato Grosso do Sul configura a violação da segurança jurídica diante a direitos humanos previstos em pactos internacionais que a República Federativa do Brasil se comprometeu em cumprir. Os principais documentos internacionais a serem explorados são: a Convenção 169 da Organização Internacional do Trabalho (OIT) e a Declaração das Nações Unidas sobre os Direitos do Povos Indígenas. A justificativa desta pesquisa se faz na Constituição Federal de 1988 que estabelece compromisso com os direitos humanos. Emprega-se a metodologia de pesquisa bibliográfica e qualitativa.

Palavras-chaves: Constituição Federal de 1988; direitos humanos; violação da segurança jurídica na anulação do território Panambi Lagoa Rica.

Abstract: The present work aims at analyzing how the annulment of the traditional Panambi Lagoa Rica territory of the Guarani Kaiowá in Mato Grosso do Sul constitutes the violation of legal security in the face of human rights foreseen in international agreements that the Federative Republic of Brazil has undertaken to comply with. The main international documents to be explored are: Convention 169 of the International Labor Organization (ILO) and the United Nations Declaration on the Rights of Indigenous Peoples. The justification of this research is made in the Federal Constitution of 1988 that establishes commitment with the human rights. The methodology of bibliographic and qualitative research is used.

\footnotetext{
*Julia Thais de Assis Moraes - Mestranda bolsista CAPES/PROSUP em Teoria Geral do Direito, pelo Centro Universitário Eurípides de Marília - UNIVEM. Graduada em Direito pela Universidade Federal de Mato Grosso do Sul, Três Lagoas (UFMS/ CPTL). E-mail : juliamoraes094@ outlook.com.

*Marco Aurélio Ranieri - Mestrando bolsista PROSUP, em Teoria Geral do Direito, pelo Centro Universitário Eurípides de Marília - UNIVEM. Graduado em Direito pelo Centro Universitário Eurípides de Marília - UNIVEM. E-mail : marcorani@hotmail.com.
} 
Keywords: Federal Constitution of 1988; human rights; violation of legal security annulment of Panambi Lagoa Rica territory.

\section{INTRODUÇÃOO}

A Constituição Federal de 1988 possui uma intrínseca relação com a ordem internacional, dialogando com a globalização de diversos ordenamentos jurídicos nacionais e supranacionais. Fato que contribui para a reconhecimento da necessidade de harmonizar decisões internas com a esfera dos direitos humanos face a esfera internacional (SARLET, 2011). Nesse sentido discute-se decisões de tribunais brasileiros que anularam demarcações de terras tradicionais, como o caso Panambi Lagoa Rica em Mato Grosso do Sul, contrariando direitos humanos previstos em documentos que a República Federativa do Brasil integra, e também direitos fundamentais indígenas previstos na Constituição de 1988.

A atual constituição se funda sob o Estado Democrático de Direito, o qual institucionaliza a proteção de garantias e direitos fundamentais destinados a todos. E acentua a proteção de setores vulneráveis da sociedade brasileira, como os indígenas, amparados pelo Capítulo VIII da Constituição de 1988. Assim, os direitos humanos ganham destaque na Carta de 1988, sendo um documento abrangente e pormenorizado sobre os direitos humanos jamais adotado no Brasil (PIOVESAN, 2018, p.77). A consolidação das liberdades fundamentais e das instituições democráticas no País, privilegiou substancialmente a política brasileira de direitos humanos, possibilitando um significativo progresso no reconhecimento de obrigações internacionais nesse âmbito.

A Constituição de 1988 passou a incorporar os direitos humanos a ordem jurídica interna, como demonstra o preâmbulo constitucional que assume o compromisso com a ordem internacional, o artigo $4^{\circ}$ II, que prevê a prevalência dos direitos humanos nas relações em que a República Federativa do Brasil seja parte, e o artigo $5^{\circ} \S 2^{\circ}$, que estabelece que direitos e garantias expressos na constituição não excluem outros decorrentes do regime e dos princípios por ela adotados, ou dos tratados internacionais que integrem a ordem jurídica interna.

A incorporação dos direitos humanos ao ordenamento pátrio gera efeitos em todo conjunto normativo. Dessa forma, as leis e procedimentos infraconstitucionais devem seguilos, a demarcação da terra tradicional Panambi Lagoa Rica seguiu o Decreto 1775/ 1996, e por consequência efetivando direitos humanos que integram a República Federativa. Contudo, a decisão que anulou o procedimento configura uma insegurança jurídica. 
A insegurança jurídica neste consiste na anulação de um procedimento que seguiu todas normas legais, e ainda que estava em consonância a direitos humanos que integram o ordenamento jurídico interno. Assim, a sentença jurídica proferida pelo juiz Anderson Moises desrespeita tantos direitos constitucionais como os direitos previstos na Convenção 169 da OIT e na Declaração da ONU sobre os Direitos dos Povos Indígena, e traz insegurança jurídica no que tange a decisões tomadas com fundamentos legais

O ordenamento pátrio estabeleceu um novo paradigma para tratar a questão indígena, sendo este da constitucionalização dos direitos indígenas, que consiste em reconhece-los em conformidade a sua identidade étnica, usos, costumes e tradições (BARBIERI, 2008, p.69). Paradigma consoante ao ordenamento internacional que reconhece os indígenas de acordo com sua origem e identidade, não podendo ser discriminados em decorrência de suas características próprias (DECLARAÇÃO DA ONU SOBRE OS DIREITOS DOS POVOS INDÍGENAS, BRASIL, 2017). E dentre os principais direitos protegidos tanto no âmbito nacional quanto internacional, tem-se o direito à terra. Visto que o direito ao território tradicional é base da cultura indígena, de suas religiões espirituais, integridade e sobrevivência material (PEGORARI, 2017, p.257).

A Constituição de 1988 determina no Capítulo VIII, artigo 231, o direito originário as terras tradicionalmente ocupadas pelos indígenas. Direito correspondente aos direitos humanos relacionados ao território tradicional, na Convenção 169 da Organização Internacional do Trabalho que prevê no artigo 14 o direito em reconhecer aos indígenas os direitos de propriedade e de posse sobre as terras que tradicionalmente ocupam. Sendo reafirmado este direito no documento mais recente de proteção aos direitos humanos atinentes aos indígenas, que é a Declaração das Nações Unidas sobre os Direitos dos Povos Indígenas, que assegura o direito as terras, territórios e recursos que tradicionalmente tenham ocupado ou adquirido.

O direito ao território tradicional é um direito fundamental face ao ordenamento interno, e direitos humanos aos indígenas, no âmbito internacional, compondo o ordenamento brasileiro, portanto deve ser efetivado. Contudo, discute-se a anulação do território tradicional Panambi Lagoa Rica, dos guaranis kaiowá em Mato Grosso do Sul, proferida em 2016, pelo Juiz Federal Moisés Anderson Costa Rodrigues da Silva, da $1^{\text {a }}$ Vara Federal de Dourados, que declarou nulo o processo de demarcação do referido território, delimitado em 2011.

Nesse sentido, o objetivo do trabalho demonstrará como a mencionada anulação judicial contraria direitos fundamentais indígenas estabelecidos na atual constituição, e direitos humanos indígenas que compõem o ordenamento pátrio. E configura um cenário de insegurança 
jurídica , no que tange a uma decisão de demarcação fundada em um decreto , que respeita todo ordenamento pátrio

\section{O direito as terras tradicionais na Constituição Federal de 1988}

A Constituição Federal de 1988 inaugurou a constitucionalização dos direitos indígenas, reconhecendo os indígenas em conformidade aos seus usos, costumes e tradições (BARBIERI, 2008, p. 69). Reconhecimento que consiste no direito à alteridade, a diferença inerente a qualquer ser humano, que é dotado de valores únicos. O Capítulo VIII se destina exclusivamente aos direitos indígenas, regulando as prerrogativas fundiárias no artigo 231 caputs e nos parágrafos seguintes (MENDES JÚNIOR, 2010).

O texto constitucional reconhece o direito as terras tradicionalmente ocupadas, no caput do artigo 231 como um direito originário, resgatando a interpretação pretérita do Alvará de $1^{\circ}$ de abril de 1680, que compreendia os indígenas como primários e naturais senhores de seus domínios (SILVA, 2016, p. 80)._Em seguida no $§ 1^{\circ}$ prescreve quatro elementos necessários a caracterizar um território tradicional, sendo estes: a) habitação em caráter permanente; b) a utilização da terra para atividades produtivas; c) serem imprescindíveis à preservação dos recursos ambientais necessários a seu bem-estar; e d) necessárias à sua reprodução física e cultural (SILVA, 2016, p. 855).

Terras tradicionalmente ocupadas, consiste no modo tradicional dos índios ocuparem e utilizarem as terras e ao modo tradicional de produção, definindo-se como a forma que se relacionam como o elemento material. A habitação em caráter permanente, relaciona-se a ideia de garantir aos indígenas um habitat futuro, no qual se realize suas tradições, protegendo-os contra eventuais esbulhos que possam sofrer (MENDES JÚNIOR, 2010, p.70). A utilização da terra para atividades produtivas se refere as atividades de subsistência como caça, pesca, em benefício coletivo (VILLARES, 2013, p.113).

As terras tradicionais devem ser imprescindíveis à preservação dos recursos ambientais necessários a seu bem-estar, segundo o mandamento constitucional. Sendo que esta imposição envolve duas perspectivas, a material e a imaterial (PEGORARI, 2017, p. 248). A material é a terra propriamente dita, que possibilita a retirada sustentável de elementos necessários a Rev. de Direitos Humanos E Efetividade | e-ISSN: 2526-0022 | Goiânia | v. 5 | n. 1 | p. 18-34| Jan/Jun. 2019 
subsistência da comunidade, e o imaterial é um local próprio que possui ligação com as crenças e rituais indígenas.

O texto constitucional posiciona o direito à terra tradicional como pressuposto para que os indígenas possuam um habitat físico, apto a garantir, sua sobrevivência física, social e cultural. A terra indígena representa um valor singular ao índio, pois é a base material da vida tradicional, sua morada, local das relações familiares e culturais, sustentando a identidade indígena (VILLARES, 2013, p. 113).

\section{Os direitos humanos face a Constituição Federal de $\mathbf{1 9 8 8}$}

A Constituição 1988 se edificou sob um Estado Democrático de Direito, trazendo o avanço na consolidação legislativa das garantias e direitos fundamentais e na proteção de setores vulneráveis da sociedade brasileira, como os indígenas. A consolidação de liberdades fundamentais e instituições democráticas possibilitaram o reconhecimento de obrigações internacionais internamente (PIOVESAN, 2018, p. 84) .

O texto constitucional se inicia estabelecendo o compromisso com a ordem internacional, sendo a primeira Constituição brasileira a estabelecer o princípio da prevalência dos direitos humanos, como princípio fundamental a reger o Estado nas relações internacionais (PIOVESAN ,2018, p. 92). Assim o artigo $4^{\circ} \mathrm{II}$, passa a dar eficácia normativa no que tange aos direitos humanos na República Federativa do Brasil, e também sinaliza uma agenda consoante a esfera a internacional.

A abertura da ordem jurídica interna ao sistema internacional (TRINDADE, 2017, p. 32) fica ainda mais clara com a previsão do artigo $5^{\circ} \S 2^{\circ}$, que estabelece que direitos e garantias expressos na constituição não excluem outros decorrentes do regime e dos princípios por ela adotados, ou dos tratados internacionais que integrem a ordem jurídica interna. Dessa maneira, os direitos humanos passam orientar o processo de elaboração de normas pátrias, e passam a representar a posição política contrária a Estados que não respeitem os direitos humanos (CRETELLA JR, 2010, p. 172).

Em resposta ao compromisso aos direitos humanos a Constituição atual regulamenta a incorporação dos tratados internacionais, estabelecendo procedimentos a serem seguidos para incorpora-los respeito. Dessarte, tratados que versarem exclusivamente acerca dos direitos humanos, quando aprovados em dois turnos, por três quintos dos votos dos respectivos membros, passam a ser equivalentes às emendas constitucionais, segundo o artigo $5^{\circ} \S 3^{\circ}$ da CF/88 (CONSTITUIÇÃO FEDERAL DE 1988, BRASIL). 
O artigo 84, VIII, determina ser competência privativa do Presidente da República celebrar tratados, convenções e atos internacionais, sujeitando-os a referendo do Congresso Nacional (PIOVESAN, 2018, p.110). Por sua vez, o artigo 49, I, do referido texto normativo prevê ser da competência exclusiva do Congresso Nacional resolver definitivamente sobre tratados, acordos ou atos internacionais. Inferindo uma cooperação entre Executivo e Legislativo na conclusão de tratados internacionais. Ressalvando que os procedimentos citados nestes dois artigos são mais simples, e, portanto, mais comuns.

\section{Direitos humanos territoriais indígenas na Convenção 169 da OIT e na Declaração da ONU dos Direitos dos Povos Indígenas}

A Convenção 169 da Organização Internacional do Trabalho (OIT), é considerada marco protetivo na esfera internacional dos direitos indígenas, estabelecendo direitos essenciais que promovem a sobrevivência física e cultural dos indígenas por meio do direito a um território tradicional. Ressalvando que a Convenção 107 da OIT sobre populações indígenas e tribais em países independentes, foi primeiro instrumento internacional tratava os direitos indígenas na esfera internacional, mas adotada a perspectiva assimilacionista ou integracionista, que discriminava a identidade indígena, não promovendo a defesa necessária os indígenas.

O direito à propriedade e à posse sobre as terras que tradicionalmente que os indígenas ocupavam foi estabelecido no texto normativo da Convenção. $\mathrm{O}$ artigo $13^{\circ}$ exige respeito dos governos ao tratarem questão territorial indígenas, em decorrência da representação especial da terra, para as culturas e valores espirituais destes. Destacando também a dimensão coletiva que a terra possui face aos indígenas (CONVENÇÃO 169 DA OIT, 1989).

$\mathrm{O}$ artigo $14^{\circ}$ determina que os Estado possuem o dever de reconhecer o direito à propriedade e à posse dos territórios tradicionalmente ocupados, garantindo sua efetiva proteção. E no artigo $18^{\circ}$ prescreve, a adoção de penalidades adequadas contra toda intrusão não autorizada nas terras indígenas ou contra todo uso não autorizado das mesmas por pessoas alheias a eles, devendo o Estado ser responsável para impedirem infrações dessa natureza (CONVENÇÃO 169 DA OIT, 1989).

A Declaração das Nações Unidas sobre os Direitos dos Povos Indígenas é o documento mais recente na proteção de direitos humanos indígenas, elaborado no ano de 2007, tratando estes direitos de acordo com situações atuais. E no referido documento os direitos territoriais indígenas são tratados de modo mais acentuado, em razão dos recorrentes conflitos que os indígenas sofrem para protegerem suas terras. 
A Declaração reconhece a urgente necessidade de respeitar e promover os direitos atinentes aos povos indígenas, que possibilitem executar suas próprias estruturas políticas, econômicas e sociais e de suas culturas, de suas tradições espirituais, de sua história e concepção de vida, elementos que são proporcionados a partir do direito às terras (DECLARAÇÃO DA ONU DOS DIREITOS DOS POVOS INDÍGENAS, 2007).

Assim, menciona no artigo $8^{\circ}$, que os indígenas têm o direito a não sofrer da assimilação forçosa ou a destruição de sua cultura, por meio de qualquer ato que tenha por objeto ou consequência alienar-lhes suas terras. Em seguida, o artigo $10^{\circ}$ estabelece a proibição dos indígenas serem retirados a força de suas terras ou territórios. Visto que para ocorrer a remoção de seus territórios, torne-se obrigatório o consentimento livre, prévio e informado, dos indígenas interessados, e a celebração de um acordo prévio a respeito de uma indenização justa e equitativa, e ainda possibilitar, quando possível à opção do regresso (DECLARAÇÃO DA ONU DOS DIREITOS DOS POVOS INDÍGENAS, 2007). E por fim o artigo 26 destaca o direito a posse das terras, territórios e recursos que tradicionalmente tenham possuído, ocupado ou de outra forma ocupado ou adquirido.

A proteção ao direito territorial indígena, possui uma conotação especial, pois difere da concepção tradicional do direito à propriedade privada, pois têm uma dimensão coletiva. Nesse sentido a Corte Interamericana assevera que: "entre os indígenas existe uma tradição comunitária sobre uma forma comunal da propriedade coletiva da terra, no sentido de que o pertencimento desta não se centra em um indivíduo, mas no grupo e em sua comunidade" (CORTE INTERNACIONAL DE DIREITOS HUMANOS, CASO DO POVO SARAMAKA VS. SURINAME, 2007). Sendo que a Convenção 169 da OIT e a Declaração da ONU sobre os Direitos dos Povos Indígenas, também sustentam a ideia central do posicionamento da Corte IDH, estabelecendo direitos que assegurem os direitos aos territórios indígenas.

\section{Incorporação da Convenção 169 da OIT e da Declaração da ONU sobre os Direitos}

\section{dos Povos Indígenas no ordenamento jurídico brasileiro}

Em 1988, foi promulgada a nova Constituição da República Federativa do Brasil que dedicou o Capítulo VIII exclusivamente aos direitos indígenas. E consoante a constitucionalização dos direitos indígenas passou a adotar documentos internacionais que assegurassem direitos humanos indígenas, a fim de fortalecer o compromisso constitucional de harmonia com a ordem internacional. E também de instrumentalizar todos dispositivos constitucionais que protegem os direitos humanos. Assim a Convenção 169 da OIT ganhou 
força para ser incorporada a ordem jurídica pátria bem como a Declaração da ONU sobre os Direitos dos Povos Indígenas.

O processo de ratificação da Convenção 169 da OIT, pelo Brasil ocorreu em 16 de julho de 1991, nos termos do artigo 49 da Constituição Federal e do artigo 19 da Constituição da Organização Internacional do Trabalho (OIT). Assim, o poder Executivo comandado pelo então Presidente Collor, submeteu a consideração do Congresso Nacional, que tardou até o ano de 2002 (URREJOLA SILVEIRA, 2016, p.5)

Em 20 de junho de 2002, por meio do Decreto Legislativo $n^{\circ}$ 143/2002, o Presidente do Senado Federal, o Senador Ramez Tebet, promulgou a aprovação do texto da Convenção 169 da OIT. Publicando o texto da Convenção no Diário Oficial da União em 21 de junho de 2002, que passou a vigorar internamente em 25 de julho de 2003, conforme o artigo 38 da Convenção (URREJOLA SILVEIRA, 2016, p.5)

A Declaração da ONU sobre os Direitos dos Povos reflete um consenso internacional mais atual sobre os direitos indígenas, adotando instrumentos mais eficazes para assegura-los. Dessa forma, sua votação foi realizada na sessão da Assembleia Geral da ONU, na qual o Brasil e mais 142 países votaram a favor do texto no Conselho de Direitos Humanos (DECLARAÇÃO DA ONU SOBRE OS DIREITOS DOS POVOS INDÍGENAS, 2009, p. 65)

O Estado brasileiro declarou perante o Conselho de Direitos Humanos da ONU, no ano de 2006, que a Declaração reafirmava o compromisso da comunidade internacional em garantir todos os direitos humanos e liberdades fundamentais aos indígenas, respeitando o valor de suas culturas e identidades. Nesse sentido, a incorporação do documento na ordem pátria se deu no momento que o Brasil aprovou a declaração na Assembleia Geral da ONU. (DECLARAÇÃO DA ONU SOBRE OS DIREITOS DOS POVOS INDÍGENAS, 2009, p. 72)

A aprovação que possibilitou a incorporação da Declaração se deu por meio do artigo 5 $\S 2$ do texto constitucional, que tem seguinte previsão: “ direitos e garantias expressos nesta Constituição não excluem outros decorrentes do regime e dos princípios por ela adotados, ou dos tratados internacionais em que a República Federativa do Brasil seja parte “ (CONSTITUIÇÃO FEDERAL DE 1988, BRASIL).

É preciso destacar que a Declaração da ONU sobre os Direitos dos Povos Indígenas não é vinculante, mas representa o compromisso da República Federativa do Brasil em cumpri normas legais internacionais. E ainda dispõe mais efetividade ao Capítulo VIII, que protege direitos indígenas na esfera interna. 


\section{Análise da decisão que anulou o território Tradicional Panambi Lagoa Rica na perspectiva dos direitos humanos}

A decisão que declarou nulo o processo demarcatório da terra Panambi Lagoa Rica fundamentou-se extensivamente na tese do marco temporal, mas também recuperou uma interpretação restritiva da tese do esbulho renitente. Assim, se analisará como a tese do marco temporal e interpretação restritiva do esbulho renitente neste julgamento, contraria os direitos humanos, previstos na Convenção 169 da OIT e na Declaração da ONU sobre os Direitos dos Povos Indígenas.

Destaca-se que a Constituição Federal de 1988 torna-se o aporte fático para as presentes ponderações, visto que há o compromisso constitucional com a ordem internacional e dispositivos normativos que torna imperativo o cumprimento dos direitos humanos no ordenamento nacional.

A Convenção 169 da OIT e a Declaração da ONU sobre os Direitos dos Povos Indígenas estabelecem um rol de direitos que devem ser assegurados pelo Estados aos indígenas. E dentre esses direitos o direito à terra é o elemento central de ambos documentos normativos, pois é pressuposto para exercerem seus usos, costumes e tradições e garantirem sua sobrevivência física e cultural. Com isso a nulidade do procedimento demarcatório Panambi Lagoa Rica contraria duplamente direitos humanos, inerentes aos indígenas.

A decisão que declarou nulo o processo de demarcação da terra indígena Panambi Lagoa Rica se fundamentou amplamente na tese do marco temporal, extraída a partir do conteúdo positivo do ato de demarcação tradicional. Assim, impôs a necessidade dos guarani kaiowa estarem ocupando os 12.196 hectares do território Panambi Lagoa Rica no dia 5 de outubro de 1988, para que este pudesse ser declarado como território tradicional, como não estavam declarou nulo o processo demarcatório.

Ainda o Magistrado seguiu a tese restritiva do esbulho renitente para corroborar a nulidade do processo demarcatório. Com o seguinte argumento na data de 5 de outubro de 1988 não há registro judicial de ação possessória pelos guarani kaiowa ou de efetivo conflito territorial com os fazendeiros que ocupavam Panambi Lagoa Rica, portanto o processo de demarcação da terra indígena teria que ser declarado nulo.

A tese do marco temporal, ao impor uma data, 5 de outubro de 1988, como data necessária que os indígenas estivessem ocupando determinado território, no caso Panambi Lagoa Rica, desconsidera o pressuposto crucial do reconhecimento de terras indígenas, que é se o território possui relação com as bases espirituais e materiais com a comunidade indígena. 
Neste aspecto, o artigo 7 da Convenção 169 da OIT que prescreve o direito dos indígenas em escolher suas, próprias terras, esvazia-se diante deste caso concreto.

Ainda na Convenção 169 da OIT no artigo 13 menciona a importância que a terra possui para os indígenas, devido sua relação com a cultura e valores espirituais. E em razão a isso os Estados devem adotar uma postura protetiva aos territórios tradicionais. Contudo no caso Panambi Lagoa Rica, o Estado representado na forma do juiz adota uma postura de não defesa aos direitos humanos territoriais indígenas, integrados com o ordenamento jurídico interno.

$\mathrm{O}$ artigo 14 da referida Convenção estabelece o dever estatal de reconhecer nos casos apropriados, medidas para resguardar o direito dos indígenas em utilizarem terras que não estejam exclusivamente ocupadas por eles, mas às quais, tradicionalmente tenham relação. Caso consoante a situação Panambi Lagoa Rica, o relatório da FUNAI colheu provas comprobatórias que as terras incluídas no município de Douradina, até a década de 1940, eram ocupadas exclusivamente pelos indígenas, com presença atestada desde o século XIX (SILVA, Y. A, 2017, p. 109). E demonstrou que a instalação da Colônia Agrícola Nacional de Dourados (CAND), gerou a invasão da área da tradicional.

Pela exposição do texto normativo dos artigos mais relevantes na proteção dos direitos humanos na Convenção 169 da OIT, infere que nenhum dispositivo impõe data determinada para que as terras possam ser reconhecidas como tradicionais. Fato que se torna compatível com as situações, como as reportadas na discussão que os indígenas foram expulsos de seus territórios, por meio de atos estatais, em grande parte violentos que objetivavam empregar suas terras para outras finalidades.

A tese restritiva do esbulho renitente também não encontra fundamento na Convenção 169 da OIT. A própria convenção estabelece, em seu artigo $3^{\circ}$ que os indígenas devem usufruir plenamente de seus direitos humanos e liberdades fundamentais, sem obstáculos (CONVENÇÃO 169 DA OIT, 1989). Ora, mas empregar uma tese que desconsidera a situações de expulsões, e exigir que uma minoria historicamente vulnerável ajuizasse uma ação possessória em 5 de outubro de 1988 é inserir propriamente um obstáculo para o exercício de seu direitos humanos e liberdades fundamentais, no que tange ao direito a terra no caso Panambi Lagoa Rica.

A Declaração da ONU sobre os Direitos dos Povos Indígenas estabelece em seu preâmbulo relacionadas as injustiças históricas vivenciadas pelos indígenas, que resultaram na alienação de seus territórios próprias (DECLARAÇÃO DA ONU SOBRE OS DIREITOS DOS 
POVOS INDÍGENAS, BRASIL, 2017). E reconhecendo necessidade de respeitar e promover os direitos intrínsecos aos indígenas, em especial os direitos às terras originárias.

A tese do marco temporal exige que os indígenas estivessem ocupando efetivamente do território Panambi Lagoa Rica na data da promulgação da CF/88. Contudo, outra prova colhida no relatório da FUNAI atesta que desde 1946 os indígenas guarani kaiowa enviavam reiteradamente ao Serviço de Proteção ao Índio (SPI), comunicando que suas terras eram invadidas e necessitavam de apoio da impedirem atos dessa natureza (SILVA, Y. A, 2017, p. 109). Dessa forma, impor uma data para que obrigatoriamente estivessem ocupando Panambi Lagoa Rica é desconsiderar provas oficiais, que mostram a impossibilidade de cumprir uma exigência inapta de cumprimento.

A Declaração da ONU prescreve no artigo 8, que os indígenas têm o direito a não sofrer da assimilação forçosa, e que os devem Estados estabelecer mecanismos efetivos para a prevenção de qualquer ato que objetive alienar terras indígenas. E o mecanismo da tese do marco temporal, empregada na decisão de nulidade da demarcação da terra Panambi Lagoa Rica, contraria este dispositivo, pois atua como um instrumento que facilita a legalização da alienação de terras tradicionais, e totalmente contraria aos direitos humanos perante a República Federativa do Brasil.

O marco temporal utilizado no caso Panambi Lagoa Rica contraria, estabelecido no artigo 10 da Declaração, que prevê que os indígenas não serão retirados pela força de suas terras ou territórios. Uma vez que os guarani kaiowa foram retirados forçosamente de suas terras, e as elas impedido de retornar, retirando também o direito de regresso previsto no artigo citado. Assim reduzir este contexto a meramente a uma exigência temporal, não se faz pertinente as todas provas colhidas pelo relatório da FUNAI que comprovou ser Panambi Lagoa Rica um território tradicional.

A tese do esbulho renitente em relação a Declaração da ONU do sobre os Direitos dos Povos Indígenas também se torna incoerente. O artigo 25 da Declaração prescreve que os indígenas têm direito em manter e fortalecer sua própria relação espiritual com as terras originárias que ocupam ou ocuparam. Assim reflete-se como torna-se possível tornar este direito possível, se a tese utilizada para analisar o caso Panambi Lagoa Rica, de imediato já coloca não haver direito devido à falta de ação possessória ajuizada em 5 de outubro de 1988, nem ao menos se atentando a provas oficiais que provam a impossibilidade de estarem ocupando Panambi Lagoa Rica, em razão de conflitos violentos. 
E por fim o artigo 26 da referida Declaração normatiza o direito aos indígenas de possuírem as terras tradicionalmente tenha possuído. No entanto, se o principal fundamento do esbulho renitente é exigir a existência de ação possessória da data de promulgação da Constituição Federal de 1988, como concretizar este direito apenas levando em consideração um fundamento tão pequeno diante de outras circunstâncias que se tornam imensas, como aquelas relatadas no relatório da FUNAI.

A declaração de nulidade do procedimento de demarcação da terra Panambi Lagoa Rica, fundada na tese do marco temporal e na tese restritiva do esbulho renitente torna-se avessa aos direitos humanos estabelecidos na Convenção 169 da OIT e na Declaração da ONU sobre os Direitos dos Povos Indígenas. E ainda enfraquece dispositivos da Constituição Federal de 1988 que preza o cumprimento de direitos humanos que integrem documentos incorporados pelo ordenamento pátrio Tais como o artigo 4, III que prevê o princípio da prevalência dos direitos, bem como ao artigo $5 \S 2$, que prevê a adoção de direitos, garantias e princípios em tratados internacionais em que a República Federativa do Brasil seja parte, como na Convenção 169 da OIT e da Declaração da ONU sobre os Direitos dos Povos Indígenas .

\section{A violação da segurança jurídica na anulação do território tradicional Panambi}

\section{Lagoa Rica}

A decisão que anulou o território tradicional Panambi Lagoa, dos guarani kaiowá em Mato Grosso do Sul, viola direitos humanos incorporados ao sistema jurídico brasileiro, e viola de modo grave a segurança jurídica de decisões fundadas em procedimento estritamente legais. A demarcação do referido território seguiu todas as fases estabelecidas no Decreto 1775/ 1996, portanto cumpriu requisitos necessários para reconhecer determinado território com tradicional.

A segurança jurídica é uma garantia da estabilidade de decisões judiciais, que passaram pelo contraditório e ampla defesa. Sendo possível interpreta-la a partir do artigo $5^{\circ}, \mathrm{XXXVI}$ do seu artigo $5^{\circ}$, que determina que “a lei não prejudicará o direito adquirido, o ato jurídico perfeito e a coisa julgada”. E esta garantia também é prevista de forma infraconstitucional, caracterizando sua importância. A previsão infraconstitucional é dada pela a Lei de Introdução ao Código Civil, que afirma em seu artigo $6^{\circ}$ que "a lei em vigor terá efeito imediato e geral, respeitados o ato jurídico perfeito, o direito adquirido e a coisa julgada”.

A partir da leitura tanto da previsão constitucional e infraconstitucional, é possível inferir que o ato jurídico perfeito é aquele já consumado segundo a lei vigente ao tempo em que se efetuou. Nesse sentido, a demarcação da terra tradicional Panambi Lagoa Rica realizada a Rev. de Direitos Humanos E Efetividade | e-ISSN: 2526-0022 | Goiânia| v. 5 | n. 1 | p. 18-34| Jan/Jun. 2019 
partir do cumprimento do Decreto 1775/ 1996, configura-se como um ato jurídico perfeito, que originando o direito adquirido aos guarani kaiowá em possuir aquele território. Ressaltando que o direito ao território tradicional é duplamente assegurado pelo presente ordenamento legal, pela Constituição de 1988, pela Convenção 169 da OIT e pela Declaração da ONU sobre os Direitos do Povos Indígenas, ambos ratificados pelo ordenamento brasileiro.

A segurança jurídica diante da demarcação da terra Panambi Lagoa Rica proporciona aos guarani kaiowá a confiança sobre seu direito originária, pois fora amparada por uma norma jurídica vigente, o Decreto 1775/ 1996. Por conseguinte, a anulação do procedimento demarcatório proferida pela decisão judicial em 2016, instaura um cenário de insegurança em relação a decisões baseadas em um ato normativo vigente. A anulação contrária efeitos jurídicos duradouros, previstos e calculados com fundamento no citado decreto.

O antônimo de segurança jurídica é propriamente a violação a segurança jurídica que é retratada nesta anulação. E os efeitos dessa violação é o retrocesso de normas protetivas a uma minoria historicamente vulnerável, que é amparada pela $\mathrm{CF} / 88$ e por normas de direitos humanos. Outro efeito é alteração de um caso já julgado, que respeitou todas fases legais préestabelecidas. E também demonstra uma tendência arbitrária de revogar atos constitutivos de direito, que fora construído embasados em provas com atestado de veracidade documental.

A violação da segurança jurídica retira princípios inerentes ao Direito, tais como da confiança e segurança, os quais proporcionam um estado de fato de Direito. Os princípios da segurança e da confiança ensejam uma dimensão objetiva da ordem jurídica que é a durabilidade e permanência da própria ordem jurídica (CANOTILHO, 2017). E consequentemente da paz jurídico social e das situações jurídicas, e legitimam a confiança na permanência das decisões jurídicas.

A anulação da terra tradicional Panambi Lagoa Rica configura a violação da segurança jurídica face ao ordenamento constitucional e principalmente a direito humanos incorporados ao ordenamento pátrio. A violação da segurança jurídica intensifica as violências históricas aos indígenas, especificamente a etnia guarani kaiowa, que sempre fora prejudicada por políticas assimilacionistas que visavam retira-los de seus territórios originários

\section{CONCLUSÃO}

A Constituição Federal de 1988 estabelece a harmonia com o ordenamento internacional no texto preambular, reiterando com eficácia normativa no artigo 4, II que prevê a prevalência dos direitos humanos nas relações da República Federativa do Brasil. E também no artigo $5^{\circ} \S$ 
$2^{\circ}$ que prevê a adoção de direitos previstos em documento internacionais que integrem o ordenamento pátrio, como a Convenção 169 da OIT e a Declaração da ONU sobre os Direitos dos Povos Indígenas.

O texto constitucional em consonância a proteção dos direitos humanos inerentes aos indígenas, inaugurou a constitucionalização dos direitos indígenas no Capítulo VIII, que são fundamentais a sobrevivência física e cultural das comunidades tradicionais. Assim, o direito à terra passa ser um direito fundamental para os indígenas, para que possam exercer seus usos, costumes e tradições, sendo estabelecido no artigo 231 e protegido nos parágrafos seguintes.

O direito as terras originárias possuem dupla proteção; a proteção interna, e a proteção dos direitos humanos, portanto se não efetivado desrespeita -se direitos fundamentais e direitos humanos. Fato que ocorreu na declaração de nulidade do processo demarcatório da terra indígena Panambi Lagoa Rica, dos guarani kaiowá em Mato Grosso do Sul. As teses empregadas, do marco temporal e do esbulho renitente contraria o próprio texto constitucional, destoando dos critérios exigidos pela Convenção 169 da OIT e da Declaração da ONU.

O caso Panambi Lagoa Rica na perspectiva dos direitos humanos, atenta-se para o desrespeito de seres humanos historicamente vulneráveis, tendo um direito integrante a sua identidade negada. Nesse sentido, o ser humano pertencente ao território Panambi Lagoa que possui sua identidade intrinsecamente ligada a questão territorial, tem negada o direito a sua personalidade, costumes e crenças.

E ainda mais a anulação da terra Panambi Lagoa Rica instaura a violação da segurança jurídica, que afeta diretamente direitos humanos e constitucionais, necessários ao bem-estar das comunidades tradicionais, neste caso da comunidade guarani kaiowá. A violação da segurança jurídica retira a principal garanti de um Estado de Direito que é a confiança e segurança, em relação a decisões jurídicas. Assim a durabilidade e permanência do ordenamento jurídico esvazia-se.

\section{Referências bibliográficas}

ALMEIDA, Alisson da Cunha. Demarcação de terras indígenas. Escola da Advocacia-Geral da União, Brasília 2005.

BARBIERI, S. R. J. Os Direitos Constitucionais dos Índios e o direito a diferença, face ao princípio da dignidade da pessoa humana. Coimbra: Almedina, 2008.

BRASIL. Constituição da República Federativa do Brasil de 1988. Disponível em: 
http://www.planalto.gov.br/ccivil 03/constituicao/constitui\%C3\%A7ao.htm . Acesso em 21 març. 2019.

. Convenção no 169 da Organização Internacional do Trabalho - OIT. Disponível em : <http://www.planalto.gov.br/ccivil_03/_ato2004-2006/2004/decreto/d5051.htm>. Acesso em 10 març. 2019

Emenda Constitucional $n^{0}$ 1, de 17 de outubro de 1969. Disponível em: < http://www.planalto.gov.br/ccivil_03/Constituicao/Emendas/Emc_anterior1988/emc0169.htm>. Acesso em 14 març. 2019.

. Declaração das Nações Unidas sobre os Direitos dos Povos Indígenas. Disponível em

https://pib.socioambiental.org/files/file/PIB_institucional/DECLARACAO_DAS_NACOES_ UNIDAS_SOBRE_OS_DIREITOS_DOS_POVOS_INDiGENAS.pdf. Acesso em 10 març. 2019.

Decreto $\mathrm{n}^{\mathbf{0}}$ 1.775, de 8 de janeiro de 1996. Dispõe sobre o procedimento administrativo de demarcação das terras indígenas e dá outras providências. Disponível em: <http://www.planalto.gov.br/ccivil_03/decreto/D1775.htm>. Acesso em: 10 març. 2019.

. Demarcação de terras. Disponível em: <http://www.ihu.unisinos.br/560862-um-anoapos-ataques-juiz-anula-demarcacao-de-terra-dos-guarani-kaiowa-ms〉. Acesso: 04 jun. 2017.

FUNAI. Disponível em: <http://www.funai.gov.br/indios/conteudo.htm>. Acesso em: 10 març. 2019.

Ministério Público Federal. Disponível em: <http://www.mpf.mp.br/atuacaotematica/ccr6/documentos-e-publicacoes/artigos/docs artigos/jose-afonso-da-silva-parecermaio-2016-1.pdf>. Acesso em: 11 març. 2019.

Ministério Público Federal: Procedimento para demarcação de terras indígenas. Disponível em : < http://www.mpf.mp.br/atuacao-tematica/ccr6/dados-da-atuacao/grupos-detrabalho/gt-demarcacao/docs/fases-do-processo-de-demarcacao-de-terras-indigenas>. Acesso em 11 març 2019.

. Portaria/FUNAI $n^{\circ}$ 14, de 09 de janeiro de 1996. Disponível em: < http://www.funai.gov.br/arquivos/conteudo/dpt/pdf/portaria14funai.pdf >. Acesso em 11 març. 2019.

\begin{tabular}{lllll}
\multicolumn{2}{c}{ Relatório circunstanciado de identificação e delimitação da terra indígena } \\
\hline Panambi & Lagoa & Rica. & Disponível & em
\end{tabular} https://www.douradosagora.com.br/base/www/douradosagora.com.br/media/attachments/93/9 3/4ee79cf4edd1c58a3d31f24cf2bd5995125ecf73d8124_portaria-524.pdf. Acesso em 11 març. 2019.

CARNEIRO DA CUNHA, Manuela. Índios na Constituição. Novos Estudos. CEBRAP, v. 37, 2018. Disponível em : < http://www.scielo.br/pdf/nec/v37n3/1980-5403-nec-37-03429.pdf>. Acesso em 12 març.2019.

CANTARINI, P, GUERRA FILHO. Proporcionalidade. Disponível em : https://enciclopediajuridica.pucsp.br/verbete/15/edicao-1/proporcionalidade. Acesso em 11 març. 2019.

CANOTILHO, J. J. GOMES. Direito constitucional. 16 ed. Coimbra: Almeida, 2016.

CAVALCANTE, Thiago Leandro Vieira. Terra Indígena: aspectos históricos da construção e aplicação de um conceito jurídico. Disponível em : < http://www.scielo.br/pdf/his/v35/0101-9074-his-35-00075.pdf> . Acesso em 12 març. 2019. 
D’ ÁVILA LOPES, MATTOS. O Direito fundamental dos indígenas à terra: do BrasilColônia ao Estado Democrático de Direito. Disponível em: < https://www2.senado.leg.br/bdsf/bitstream/handle/id/92744/Lopes\%20Ana\%20Maria\%20e\% 20Mattos\%20Karine.pdf?sequence=1>. Acesso em 13 març. 2019.

FRANCO F. UM OLHAR INDÍGENA sobre a Declaração das Nações Unidas. Disponível em : 〈 http://www.dhnet.org.br/direitos/sip/onu/indios/um olhar indigena versao final.pdf $>$. Acesso em 13 març. 2019.

FREITAS JÚNIOR, L. A posse das terras tradicionalmente ocupadas pelos índios como um instituto diverso da posse civil e sua qualificação como um direito constitucional fundamental. Dissertação para obtenção de título de Mestre, UNIFOR. Disponível em: < http://www.dominiopublico.gov.br/download/teste/arqs/cp127773.pdf >. Acesso em 12 març. 2019.

MAIA, L. M. Do papel da perícia antropológica na afirmação dos direitos dos índios. In: OLIVEIRA, João Pacheco; MURA, Fábio; SILVA, Alexandre Barbosa da. (Org.). Laudos antropológicos em perspectiva. 1. ed. Brasília: Aba Publicações, 2015.

MARQUES, Júlia Ribeiro. A Constituição Federal e o Direito dos Povos Indígenas à Terra: Uma análise da Decisão do Supremo Tribunal Federal sobre a demarcação da terra indígena Raposa Serra do Sol. Disponível em: <http://www3.pucrs.br/pucrs/files/uni/poa/direito/graduacao/tcc/tcc2/trabalhos2012_1/julia_m ar ques.pdf. >. Acesso em 15 març.2019.

MENDES JÚNIOR, João. Os indígenas do Brasil, seus direitos individuais e políticos. Edição Fac-Similar. São Paulo: Typ; Hennies Irmãos, 1912.

MINISTÉRIO DA JUSTIÇA. Jurisprudência da corte interamericana de direitos humanos direitos dos povos indígenas. Disponível em : < http://www.mpf.mp.br/atuacaotematica/ccr6/documentos-e-publicacoes/artigos/docs_artigos/jurisprudencia-corteinteramericana-direitos-dos-povos-indigenas.pdf>. Acesso em 16 març.2019.

PEGORARI, Bruno. A tese do marco temporal da ocupação como interpretação restritiva do direito à terra dos povos indígenas no Brasil: um olhar sob a perspectiva da Corte Interamericana de Direitos Humanos. Aracê - Direitos Humanos em Revista, v. 4, p. 246262, 2017.

PIOVESAN, F. Internacionalização dos direitos humanos e humanização do Direito Internacional: desafios contemporâneos. Boletim da sociedade brasileira de direito internacional, v. 103, 2017.

Temas de Direitos Humanos. 11. ed. São Paulo: Saraiva, v. 1., 2018.

. Direitos Humanos e o Direito Constitucional Internacional. 18. ed. São Paulo:

Saraiva, v.1, 2018.

SARLET, I. W. Considerações a respeito das relações entre a constituição federal de 1988 e os tratados 
Internacionais de direitos humanos. Disponível em : https://juslaboris.tst.jus.br/bitstream/handle/20.500.12178/28337/006_sarlet.pdf?sequence=3. Acesso em 10 marc.2019.

SILVA, Y. A, Estudo do conflito agrário pela posse das terras tradicionais dos povos indígenas guarani kaiowá no mato Grosso do Sul. Dissertação para obtenção de título de Mestre, UFG. Disponível em: < https://repositorio.bc.ufg.br/tede/handle/tede/8206>. Acesso em 13 març. 2019.

UNESCO. Declaração das Nações Unidas sobre os Povos Indígenas: perguntas e respostas. 2.ed. - Rio de Janeiro: UNIC; Brasília, 2009. Disponível em : http://unicrio.org.br/docs/declaracao_direitos_povos_indigenas.pdf. Acesso em 13 març. 2019.

URREJOLA L C F. Organizações Internacionais e as Comunidades Indígenas na América Latina: o caso da Convenção $n^{0} 169$ da Organização Internacional do Trabalho (OIT) e o processo de consulta prévia na Argentina, Brasil e Chile. Disponível em : https://sites.usp.br/prolam/wp-content/uploads/sites/35/2016/12/Laura Urrejola II-SimposioInternacional-Pensar-e-Repensar-a-America-Latina.pdf. Acesso em 13 març. 2019.

VILLARES, Luiz Fernando. Direito e povos indígenas. Curitiba: Juruá, 2009. 